\title{
BTEX and nitrogen oxides fume assessments in fuel dispense stations and residential areas
}

\author{
Raslan A.Alenezi \\ Department of Chemical Engineering, College of Technological Studies, Public Authority for Applied Education and Training, \\ Shuwaikh 70654, Kuwait. \\ Corresponding Author: Ra.alenezi@paaet.edu.kw
}

Submitted : 27/03/2021

Revised : 30/06/2021

Accepted : 11/07/2021

\begin{abstract}
Fuel vapors are released from storage tanks through vent pipes and from filling pump fuel dispensary stations. These petroleum-based by-products are introduced into ambient atmospheres and neighboring areas and may become a potential health risk. To investigate the quantity of benzene, toluene, ethylbenzene, xylene (BTEX), and nitrogen oxides (NOx) concentrations as they are considered air pollutants and proven that they have negative health impacts on human, a selected fuel dispensing stations within Kuwaiti residential areas and passive samplers were deployed within selected fuel stations and also several residential areas for one week. Findings reveal that the concentration of BTEX at the fuel dispensing stations was significantly elevated than it was for the breathing pipe in residential areas. The concentration of benzene of $5.5 \mu \mathrm{g} / \mathrm{m}^{3}$ is slightly higher than the mean ambient concentrations in the rural and urban areas, $1 \mu \mathrm{g} / \mathrm{m}^{3}$ and 5-20 $\mu \mathrm{g} / \mathrm{m}^{3}$, respectively. The levels are higher near such sources of benzene emission as fuel dispensing stations. As a result, the benzene close to the fuel stations becomes higher, $70 \mu \mathrm{g} / \mathrm{m}^{3}$. Emissions escalate during weather change because of meteorological variables like temperature and wind direction influence dispersion of noxious compounds in the ambient air. With significant additions of harmful petroleum products into Kuwaiti air, a weary for respiratory and digestive implications may be paving the way to cause an ecological uproar. Hence, the government should use this baseline data and provide guidance to fuel dispensary stations for an improved method of fuel dispense, improvising fuel storing to minimise temperature change for fuel state preservation and use of nozzles that increase dispensary speeds while minimising vapour production.
\end{abstract}

Keywords: Ecology; Public health; Fuel; Community; Healthy air; Air pollution.

\section{INTRODUCTION}

Ambient air is appreciated in many countries because industrialization has caused impoverishment to both living and nonliving organisms. This impoverishment is not only limited to the quantity of perquisite particle intake, but also limited to deterrents that may lead to acute or chronic ailments. Therefore, air has become a natural asset and a basic requirement for human health and well-being. Moreover, it is crucial to maintain air quality that abides by the standards of World Health Origination (WHO), so that ambiance is maintained and risks for respiratory and cardiovascular diseases are reduced (Oturakci et al., 2020; WHO, 2000). Pursuing ambient air is no longer a country 
concern, but it has become an international concern. The yearly deaths due to air pollution worldwide are estimated to be 6.57 million as stated by an annual comprehensive report in 2020. It is an indication that the surrounding air quality should not be compromised by pollutants. Air pollution reduces the efficacy of earth cycles, which then reduces the ability of the environment to clean itself (Al-Harbi et al., 2020; Bouhamra and Abdul-Wahab, 1999). Reduction of air quality is mainly caused by ineffective regulations and awareness that are now implicating finance and lives annually (Abdul-Wahab, 2008; AlRukaibi et al., 2021).

In recent turmoil, Kuwait and gulf countries are suffering from deteriorated air after heavily consuming fossil fuels. These are divided into upstream (drilling, production, processing, transporting, and storage) and downstream (refining, blending, storage, distribution, and dispensing) activities, and the scorching heated climate, $50^{\circ} \mathrm{C}$, has made airborne pollutants easily acquired during respiratory intake. Thus, health implications from polluted air result in chronic diseases and cancers. Now, it is a community crisis, since the region's $3.4 \%$ annual population growth is supported by young generations. To make matters worse, all official and residential buildings are air-conditioned, and $80 \%$ of the population incarcerates themselves in microenvironments (Alenezi et al., 2012).

Since indoor air quality is influenced by municipal air, pollutants, and local emissions from cooking combustible products, volatile organics from paints, adhesives, cosmetics, insecticides, fresheners, and other building materials, health implications are inevitable.

One of the many point sources for pollutants is fuel dispensing stations because they emit volatile organic compounds (VOCs).Worryingly, an annual $9 \%$ increase of motor vehicles in operations throughout Kuwait has created massive gasoline demands. To avoid fuel supply shortages, Kuwait National Petroleum Company has set up 45 fuel dispensing stations, with priorities to major cities like Al-Jahra and Al-Aasmah (Kuwait Petroleum Cooperation, 2017). In addition, locations for gasoline stations are not specified nor their abundance regulated in Kuwait and surrounding countries. Comparatively, Canada has established 44 guidelines for urban design and location of placements to minimize the impacts from fuel station discharges and weather conditions (Elkilani and Bouhamra, 2001).These stations actively dispense fuel throughout the day, and the amount of volatile compounds emitted significantly contributes to urban air pollution, particularly in a nearby residential neighbourhood. Pollutant laced air vapour mixes with clean air to become a reservoir and saturation highly pertains to weather exhibits (Correa et al., 2012). The Clean Air Act 1990 has classified OC as hazardous with benzene (group 1 carcinogen), toluene, ethylbenzene (group 2B carcinogen), and all xylene isomers (BTEXs) as mutagenic and carcinogenic.

Since the geographical topography for each country varies with related meteorological conditions, this article presents the effect of petroleum-based fuel dispense in stations toward air quality around its vicinity. As knowledge goes, gasoline and diesel dispensing stations release vapours containing a mixture of light hydrocarbons like BTEX (benzene, toluene, ethylbenzene, and xylene), whereas emission from vehicles releases nitrogen oxides. However, the quantity of vapour release at fuel dispensing stations and its impacts on residential areas in Kuwait remains unascertained, and this gives the present initiative an advantage in the field.

\section{METHODS AND MATERIALS}

\section{Sample Collection and Analysis}

Several passive samplers (BTEX and NOx) were purchased from IVL Swedish Environmental Research Institute Ltd. In this study, five fuel dispensing stations situated within $200 \mathrm{~m}$ from residential areas were identified. The selection of fuel dispenses stations includes the presence of residential buildings, accessibility, and demand (fuel sale). Specifications and placement of passive samplers were adopted from Ferm et al. (Ferm et al., 2005). Two sets of passive samplers were assembled in the northwest downwind direction for every fuel dispensing station, whereas 
another two sets were assembled in the nearby residential area (Figure 1). Each sampler being able to trap BTEX ((benzene, toluene, ethylbenzene, $\mathrm{m}, \mathrm{p}$-xylene, and o-xylene) and $\mathrm{NO}_{\mathrm{x}}$ vapours was placed on the breathing pipe that lay overhead the underground fuel storage tank, whereas another set is placed above the fuel dispenser. Also, forty (40) residential areas were identified for the study, from which one set of samplers was attached to gate or fence, while another unit was fitted indoor of the random house situated adjacent to the test fuel station. All samples were kept in the study site for 7 days, and sample collection was carried out every day. As shown in Figure 2, the predominant wind rose plot for the entire country of Kuwait showed a north-westerly prevailing wind assumption of the high concentration of air pollutants in the downwind direction (Alenezi and Aldaihan, 2019).

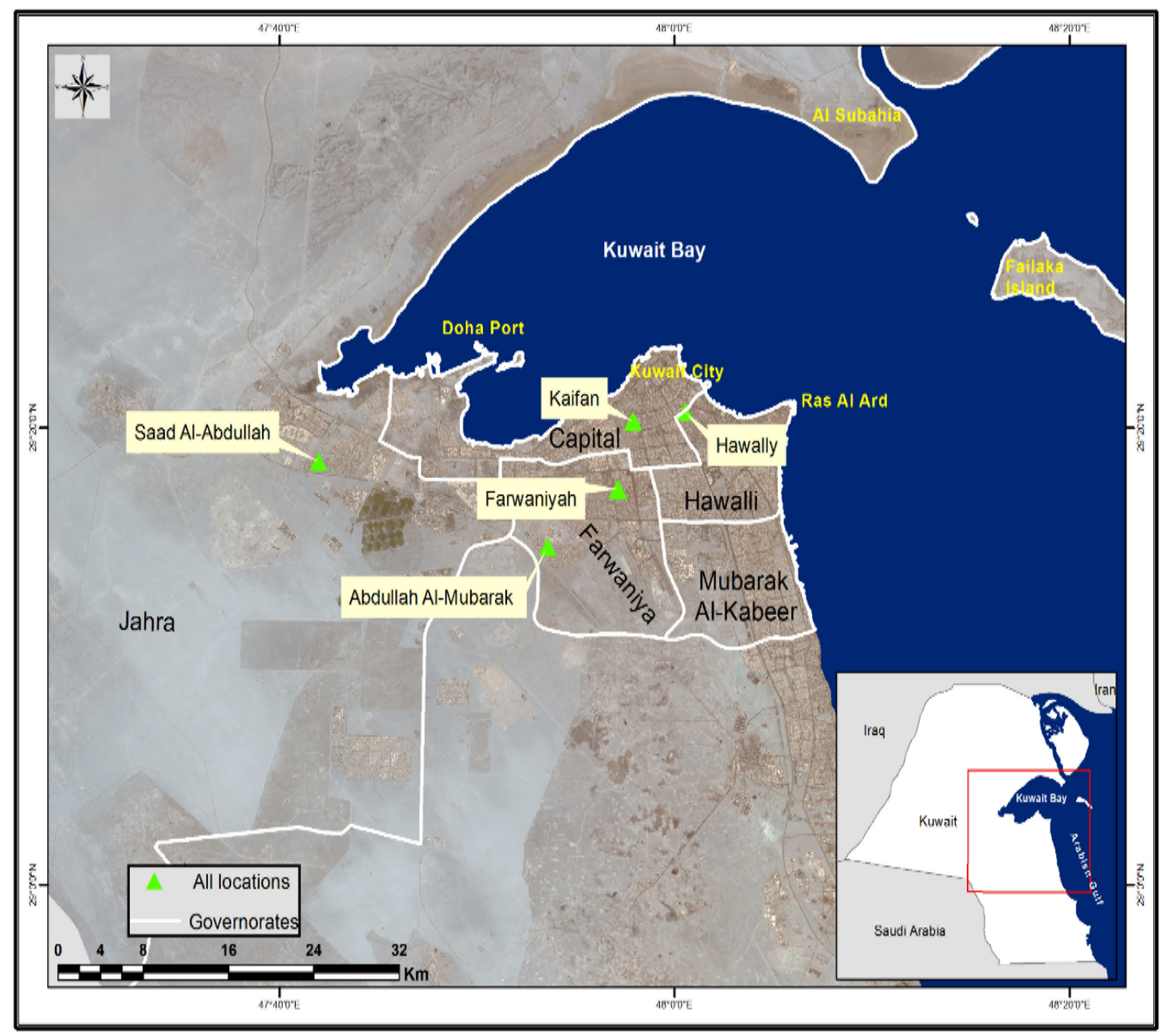

Figure 1. Selection of 5 major cities in Kuwait for the passive sampler placement in fuel dispensing stations and residential areas. 


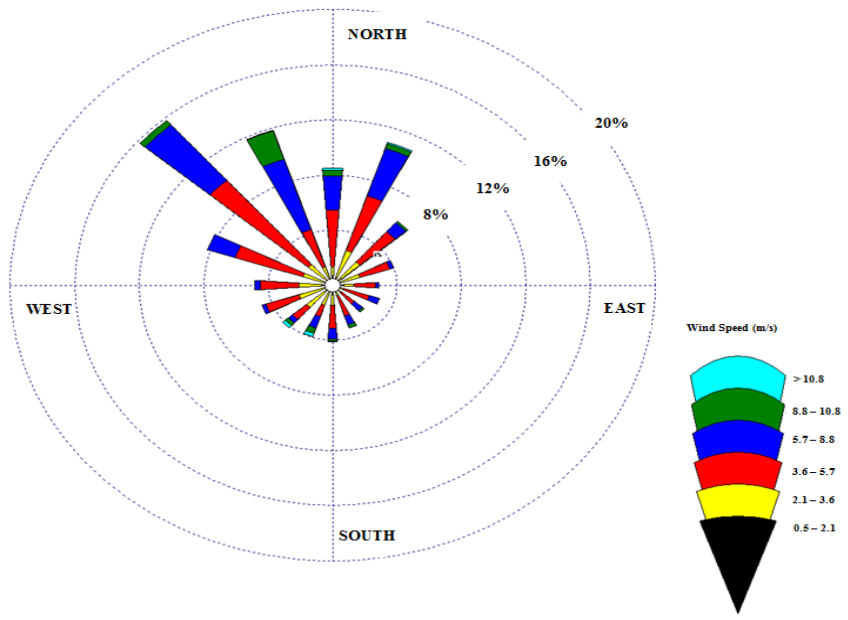

Figure 2. The predominant wind rose plot for the state of Kuwait.

\section{Data Analysis}

The data were first aligned into time-based concentration values before inserted into GraphPad Prism v.7 for one-way analysis of variance (ANOVA). Then, another batch of data was inserted into the similar software for linear correlation analysis with benzene as reference. All outliers were removed in GraphPad Prism v.7, and data were expressed as mean \pm standard deviation.

\section{RESULTS}

The air temperature of all study sites, namely, Farwaniya, Abdullah Al-Mubarak Al-Sabah, Saad Al-Abdullah (Jahra), Kaifan, and Hawally, ranged between $24^{\circ} \mathrm{C}$ and $28^{\circ} \mathrm{C}$, while wind speeds were between $5 \mathrm{~ms}^{-1}$ and $12 \mathrm{~ms}^{-1}$. Kuwait faces northwest and southeast winds that average $9 \mathrm{~m} \mathrm{~s}^{-1}$ year-round to state that Kuwaiti winds channel volatile gases along its path. Therefore, although fuel storage depots of Jahra $(p=0.05)$, Kaifan $(p=0.001)$, and Hawally $(\mathrm{p}=0.001)$ were bleeding volatile BTEX at $155 \mu \mathrm{g} \mathrm{m}^{-3}, 92 \mu \mathrm{g} \mathrm{m}^{-3}$, and $122 \mu \mathrm{g} \mathrm{m}^{-3}$ into the environment, fuel dispensing stations in Farwaniya $(\mathrm{p}=0.001)$ and Hawally $(\mathrm{p}=0.001)$ are responsible for $326 \mu \mathrm{g} \mathrm{m}^{-3}$ and $405 \mu \mathrm{g} \mathrm{m}^{-3}$ BTEX that escaped into ambient air (Figure 3). Hazardous volatile fumes were retaining within homes erected in Abdullah Al-Mubarak Al-Sabah $(\mathrm{p}=0.001)$ and Kaifan $(\mathrm{p}=0.001)$ because $35 \mu \mathrm{g} \mathrm{m}^{-3}$ and $71 \mu \mathrm{g} \mathrm{m}^{-3} \mathrm{BTEX}$ were recorded. Comparatively, the air of residential areas in Jahra, Kaifan $(\mathrm{p}=0.001)$, and Hawally was only containing $26 \mu \mathrm{g} \mathrm{m}^{-3}, 26 \mu \mathrm{g} \mathrm{m}^{-3}$, and $34 \mu \mathrm{g} \mathrm{m}^{-3}$ BTEX (Figure 4). Petroleum by-products evaluated as nitrogen oxides $\left(\mu \mathrm{g} \mathrm{m}^{-3}\right)$ were at $102 \mu \mathrm{g} \mathrm{m}^{-3}, 111 \mu \mathrm{g} \mathrm{m}^{-3}$, and $105 \mu \mathrm{g} \mathrm{m}^{-3}$ in fuel storage depots of Abdullah Al-Mubarak Al-Sabah, Kaifan, and Hawally cities. It was different for fuel dispensers of Farwaniya $(p=0.001)$, Abdullah Al-Mubarak Al-Sabah ( $p$ $=0.05$ ), and Hawally cities with the values $130 \mu \mathrm{g} \mathrm{m}^{-3}, 81 \mu \mathrm{g} \mathrm{m}^{-3}$, and $96 \mu \mathrm{g} \mathrm{m}^{-3}$ (Figure 5). Concentrations of nitrogen oxides in indoor units $(\mathrm{p}=0.05)$ were alarming in Jahra $\left(98 \mu \mathrm{g} \mathrm{m}^{-3}\right)$ and Hawally $\left(114 \mu \mathrm{g} \mathrm{m}^{-3}\right)$ because international standards only permit $30 \mu \mathrm{g} \mathrm{m}^{-3}$ of nitrogen oxides in the air (Figure 6). Concentrations of BTEX components like toluene, ethylbenzene, and o-xylene, as well as nitrogen oxides, were strongly correlated $\left(\mathrm{R}^{2}=0.9\right)$ with benzene, especially with the breathing pipe in the fuel storage depot $\left(R^{2}=0.91-0.98\right)$ and fuel dispenser $\left(R^{2}=0.94-0.96\right)$ (Figures 7a and 7b). Correlation values between $R^{2}=0.0002$ and $R^{2}=0.94$ were produced for BTEX and nitrogen oxides from residential areas (Figures $7 \mathrm{c}$ and $7 \mathrm{~d}$ ). 


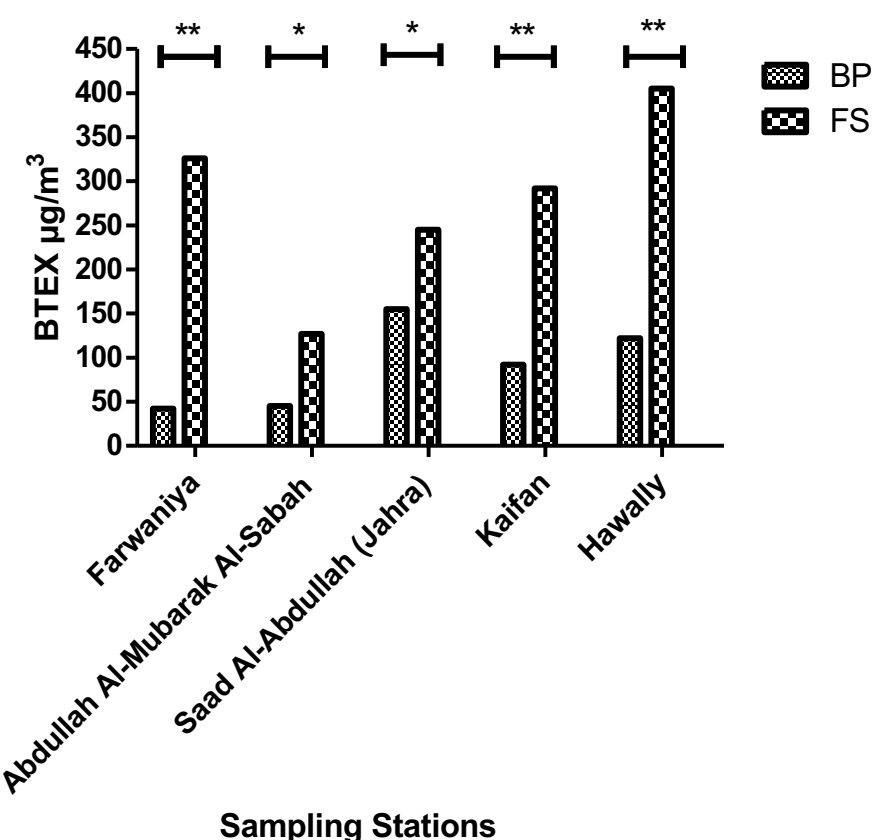

Figure 3. Concentrations of BTEX were observed in breathing pipe and filling station in different sampling locations. Note: $*=P<0.05$; $* *=P<0.001$. BP: breathing pipe; FS: filling station.

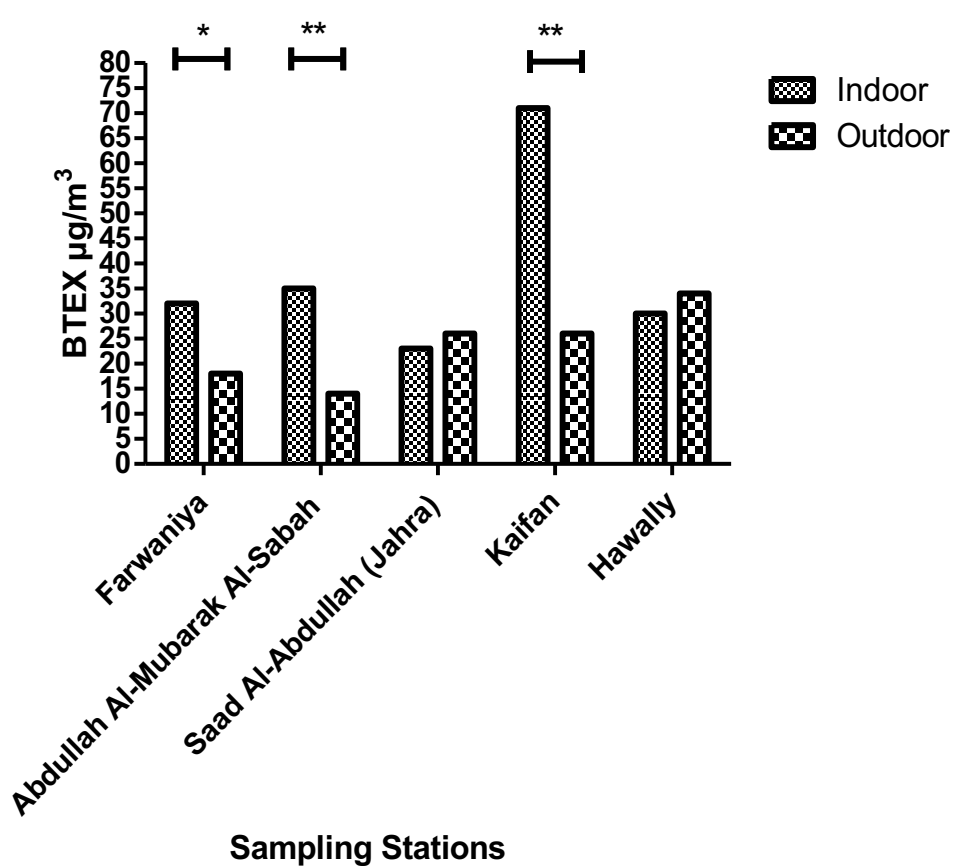

Figure 4. Concentrations of BTEX were observed in indoor and outdoor units (samplers placed in the residential area) in different sampling locations. Note: $*=P<0.05$; $* *=P<0.001$. 


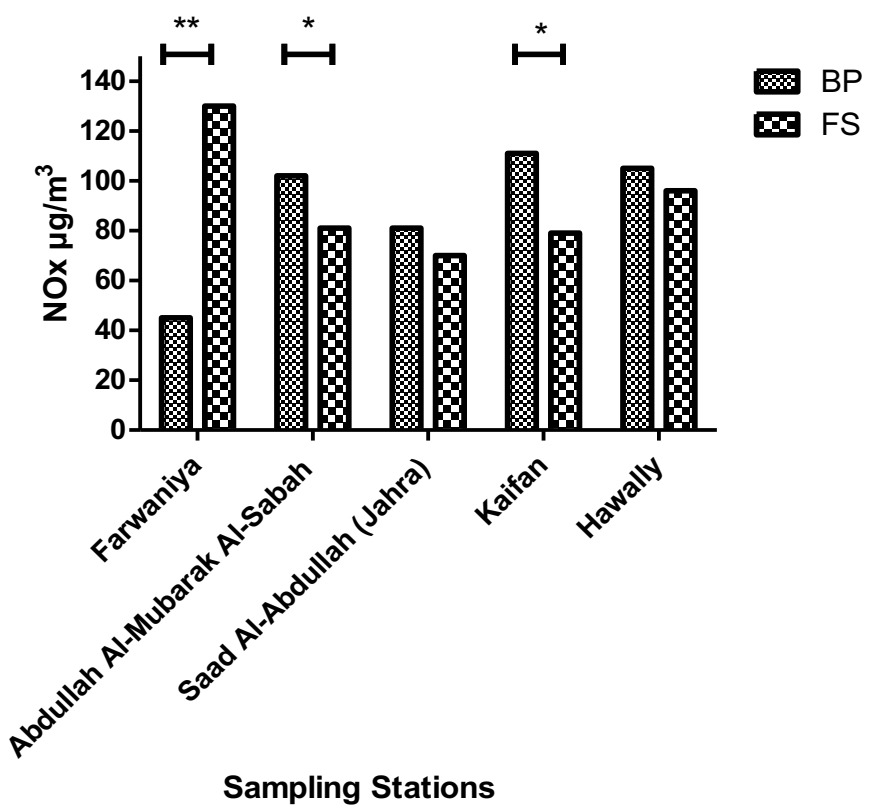

Figure 5. Concentrations of NOx were observed in breathing pipe and filling station in different sampling locations. Note: $*=P<0.05 ; * *=P<0.001$. BP: breathing pipe; FS: filling station.

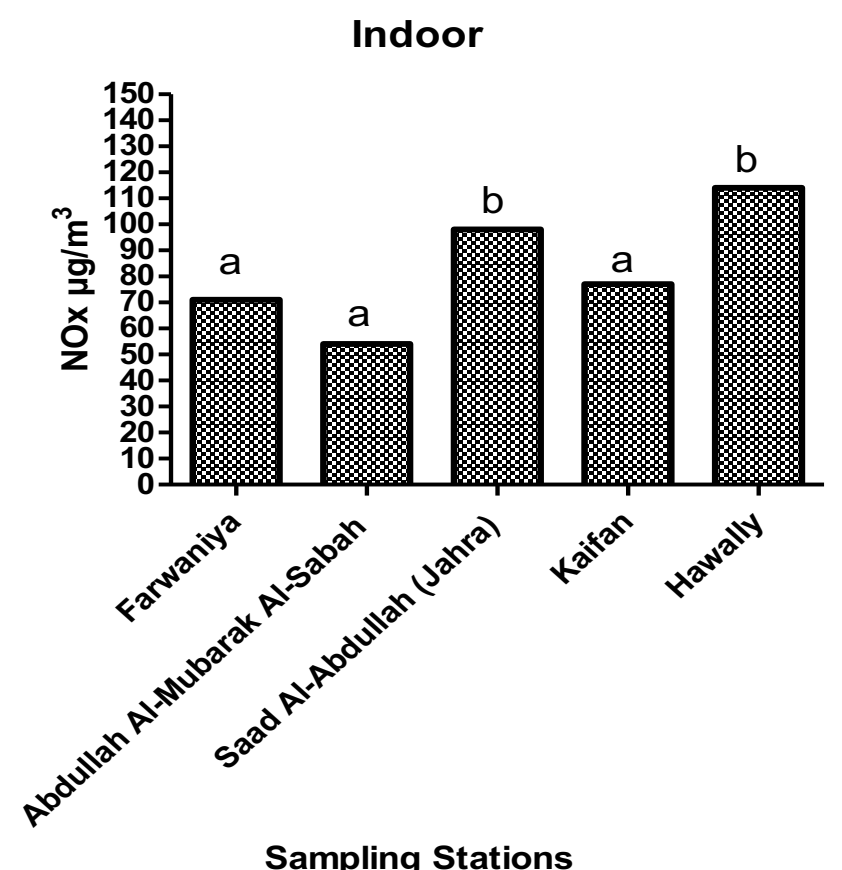

Figure 6. Concentrations of NOx observed in indoor units (samplers mounted inside the home in the residential area). Note: different alphabets in each column show a significant difference in NOx concentration between sampling stations at a $95 \%$ confident interval. 
(a)

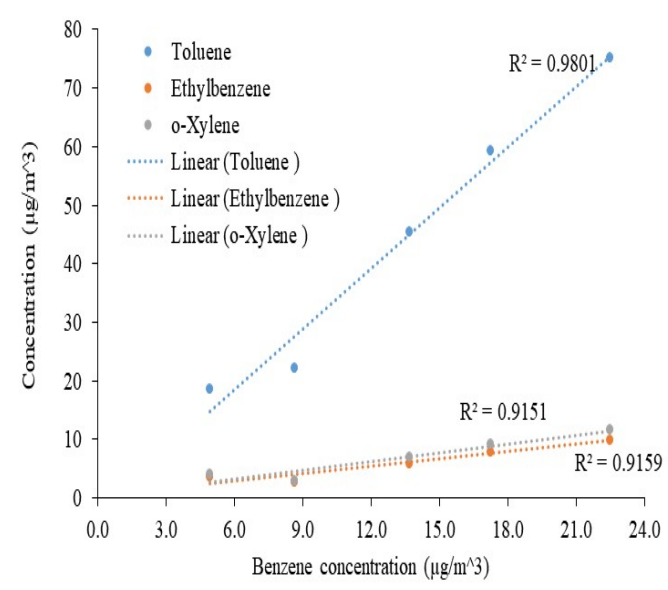

(c)

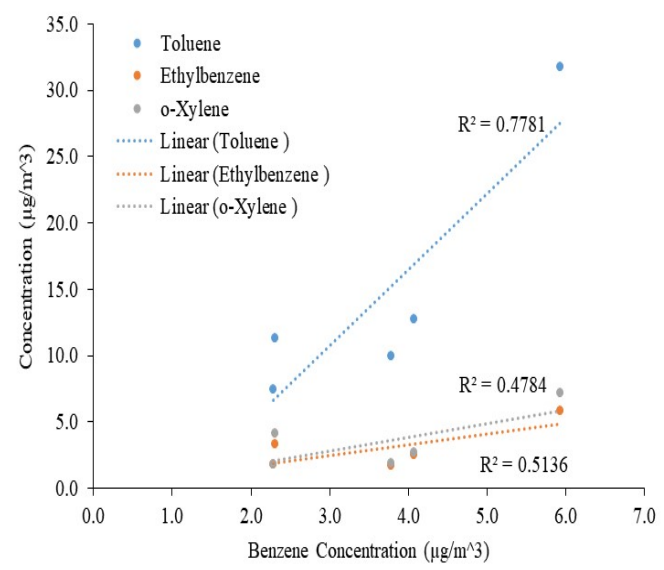

(b)

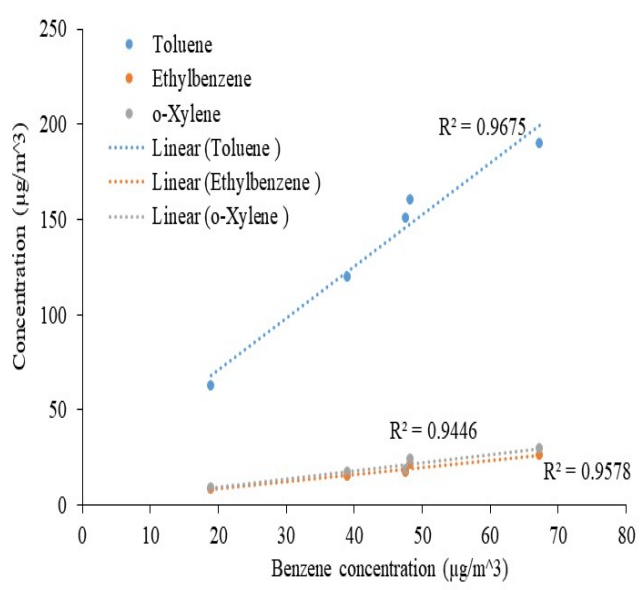

(d)

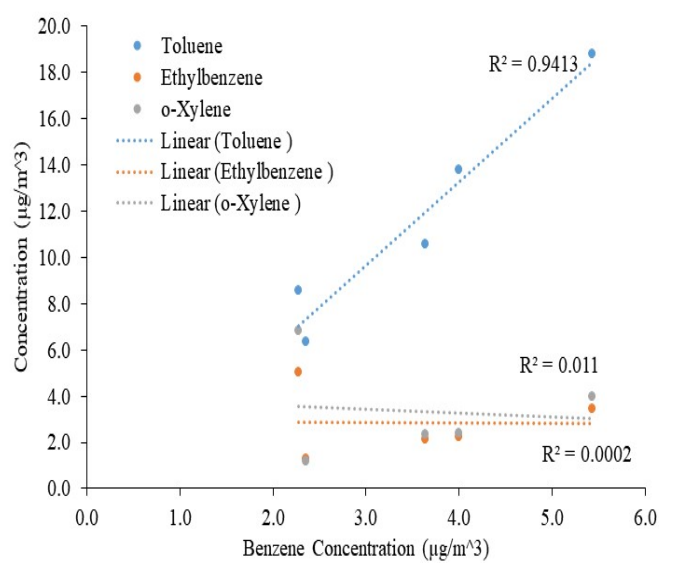

Figure 7. Linear regression analysis on different pairs of pollutants by considering benzene as a reference in all sampling stations. Note that Figures $7 \mathrm{a}, 7 \mathrm{~b}, 7 \mathrm{c}$, and $7 \mathrm{~d}$ represent the concentration of pollutants in breathing pipe, fuel dispensing stations, and indoor and outdoor units, respectively.

\section{DISCUSSIONS}

Benzene was treated separately in BTEX due to its carcinogenic and mutagenic properties (Linet et al., 1996), from which fuel stations of Kuwait were emitting toluene, benzene, o-xylene, and ethylbenzene in reducing order. Fuel dispensing stations in India (Srivastava et al., 2006) and Europe (Cerón-Bretón et al., 2015) were indicating that benzene-based fumes predominated the gaseous compositions, but breathing pipe of fuel storage and fuel dispensers of Kuwait are indicating otherwise. Another report from the middle east also affirms that benzene is not predominantly released from fuel dispensing stations (Dehghani et al., 2018). It is a clear-cut indication that petroleum distillation reconfigures fossil fuel composition and it varies with weathering and extraction conditions.

Despite the reduced quantity of benzene fumes, BTEX composition in the air from both indoor and outdoor residential sites, the concentrations of airborne benzene related to an additional lifetime risk of 1/10 000, 1/100 000, and $1 / 1000000$ are $17,1.7$, and $0.17 \mu \mathrm{g} / \mathrm{m}^{3}$, respectively. Moreover, as a result of exposure to benzene, the cancer risk for adult and child populations was estimated to be 7 in 1,000,000 and 1 in 100,000, respectively (WHO, 2010). The concentration of benzene of $5.5 \mu \mathrm{g} / \mathrm{m}^{3}$ is slightly higher than the mean ambient concentrations in the rural and 
urban areas, $1 \mu \mathrm{g} / \mathrm{m}^{3}$ and 5-20 $\mu \mathrm{g} / \mathrm{m}^{3}$, respectively. As shown in Figure 3, the concentration of BETX is high, up to 400 and $150 \mu \mathrm{g} / \mathrm{m}^{3}$ in the breathing pipe and fuel dispensing stations. The level of concentration is higher near such sources of benzene emission, as fuel dispensing stations. As a result, the benzene concentration close to the fuel stations becomes higher, up to $70 \mu \mathrm{g} / \mathrm{m}^{3}$. These concentrations are considered high due to being close to the source and ambient temperatures and in agreement with WHO guidelines for indoor air quality (WHO, 2010). Also, another contributor to these concentrations is the emissions from neighbouring road traffic.

Benzene is considered a carcinogenic agent, and has been indicative of severe toxicity, such as leukemia and hematotoxicity (Dehghani et al., 2018; Durmusoglu et al., 2010; Miri et al., 2016; Rezazadeh Azari et al., 2012). As benzene is exposed to humans, two proteins, epoxide and benzoquinone adducts, are created in human blood. Moreover, benzene prompts oxidative stress if exposed to humans and human cells. Other compounds in gasoline such as toluene, ethylbenzene, and xylene have similar toxicities with neurological effects (IARC:, 2012). Janitz et al., (2017) found that acute leukemia is related to increased benzene exposure during early-maternity periods. Though wind direction is accountable for enriched concentrations of BTEX in air, proximity, and travel distance to reach the passive sampler, air temperature also plays a role for fume preconcentration, while fumes from fuel dispensers move towards residential areas.

The BETX concentrations for the indoor and outdoor residential areas are demonstrated in Figure 4. As expected, normally the indoor concentrations of BETX are higher than the outdoor in agreement with Elkilani and Bouhamra (Elkilani and Bouhamra, 2001) because of the contribution of internal sources such as the renovation of the house and internal refurbishing and perfumes. Figures 3 and 4 revealed that the concentrations of BETX for a fuel dispensing station were significantly higher than those for indoors and outdoors.

The average $\mathrm{NO}_{\mathrm{x}}$ concentration of the breathing pipe of the fuel storage tank and filling stations is shown in Figure 5. The concentration of NOx reflects heavy road traffic in the fuel stations (Al-Harbi et al., 2020). The NOx concentrations in Figure 6 for indoor show a significant difference between sampling points at a 95\% confident interval. This can be justified as different locations due to physical obstruction of some construction.

A linear regression analysis on different pairs of pollutants by considering benzene as a reference in all sampling stations is shown in Figure7. Similarly, the concentration of benzene related to toluene, o-xylene, and ethylbenzene is higher than that in indoor and outdoor. The highest ratio between benzene and toluene is shown around the fuel dispensing stations as a result of leaking from filling hoses and fuel fumes.

The additional presence of nitrogen oxides creates synergetic interactions between air particles and atmospheric sulphides to create polluted air (Dohmen et al., 1984). Added with poor ventilation, volatile fumes become entrapped indoor and tend to increase concentration in the presence of carbonized particles (Elkilani and Bouhamra, 2001). Hence, fumes trapped indoor could increase in concentrations through gaseous partitioning effects or with building materials if compared to fumes that already occur in the outdoor environment ( $\mathrm{Li}$ and Niu, 2005). Gasoline vaporizes at low temperatures between $24{ }^{\circ} \mathrm{C}$ and $40{ }^{\circ} \mathrm{C}$ depending on the number of additives and weather conditions are highly responsible for the transition of fuel state (Kountouriotis et al., 2014). Perhaps the availability of volatile organic constituents like BTEX and nitrogen oxides into the air is influenced by heat generated from vehicles during fuel dispense, the number of vehicles, and the quantity of fuel dispensing stations (Terrés et al., 2010). Considering this fact, Kuwait Petroleum Corporation (KPC) has decided to build 100 new modern gas stations with the latest ecofriendly technologies to meet future demand. Nevertheless, the use of eco-friendly technology with newly adopted fuel dispersing station design and the application of a renewable and alternative energy concept would help in reducing the toxicant level in ambient air. 


\section{CONCLUSIONS AND RECOMMENDATIONS}

In the current study, we assessed the personal exposure for indoor and outdoor and ambient concentrations of BETX and NOx near fuel dispensing stations. Presently, BETX and nitrogen oxides are enriched at the Hawally fuel dispensing station. Apart from its location in the city centre, the air in this vicinity constantly received combusted fumes from heavy vehicle congestions. Separately, residential areas of Kaifan are threatened by increased concentrations of BTEX in ambient air. Though drift winds and flattened ground ease fume transportation of fumes from point sources, it is the structure design and material that allows retention and entrapment of BTEX fumes. The personal exposure concentrations of BETX were significantly higher than their indoor and ambient concentrations. Unpromisingly, BETX and nitrogen oxides in Kuwaiti air have a high level. So, there is support from the study to reconsider setback distances for fuel dispensing stations from residential areas. In addition, studies on aliphatic, aromatic, oxygenated, and halogenated compounds must be carried out at fuel dispensing stations so that a vapor recovery system may be developed to control fuel emissions from the filling nozzle. This reduces the exposure time to both, fuel station employees and the community in Kuwait.

\section{ACKNOWLEDGMENT}

The author acknowledges the support provided by the Public Authority for Applied Education and Training (PAAET), (Grants No. TS-14-002).

\section{REFERENCES}

Abdul-Wahab, S.A., 2008. A preliminary investigation into the environmental awareness of the Omani public and their willingness to protect the environment. American Journal of Environmental Sciences. 4: 39-49.

Al-Harbi, A.A., Alenazey, F.S., Binjuwair, S.A., Alshunaifi, I.A., Alkhedhair, A.M., Alabduly, A.J., Almorat, M.S., Albishi, M.S., 2020. Reducing NOx emissions by adding hydrogen-rich synthesis gas generated by a plasma-assisted fuel reformer using Saudi Arabian market gasoline and ethanol for different air/fuel mixtures. Journal of Engg. Research. 8: 1-16.

Alenezi, R., Al-Anzi, B., Abusam, A., Ashfaque, A., 2012. Seasonal influence on the ambient air quality in Al Jahra City for year 2010. Journal of Environmental Protection. 3: 1711-1718.

Alenezi, R.A., Aldaihan, N., 2019. Impact of fuel dispensing stations in the vicinity residential homes on the indoor and outdoor air quality. International Journal of Environmental Science and Technology. 16: 2783-2796.

AlRukaibi, F., AlRukaibi, D., AlBurait, A., Al-Mutairi**, A., 2021. The Impact of Congestion Charging Technique on Traffic Flow and Atmospheric Pollution in Kuwait City . Journal of Engg. Research. 9: 51-62.

Bouhamra, W., Abdul-Wahab, S., 1999. Description of outdoor air quality in a typical residential area in Kuwait. Environmental pollution. 105: 221-229.

Cerón-Bretón, J., Cerón-Bretón, R., Kahl, J., Ramírez-Lara, E., Guarnaccia, C., Aguilar-Ucán, C., MontalvoRomero, C., Anguebes-Franseschi, F., López-Chuken, U., 2015. Diurnal and seasonal variation of BTEX in the air of Monterrey, Mexico: preliminary study of sources and photochemical ozone pollution. Air Quality, Atmosphere \& Health. 8: 469-482.

Correa, S.M., Arbilla, G., Marques, M.R., Oliveira, K.M., 2012. The impact of BTEX emissions from gas stations into the atmosphere. Atmospheric pollution research. 3: 163-169. 
Dehghani, M., Fazlzadeh, M., Sorooshian, A., Tabatabaee, H.R., Miri, M., Baghani, A.N., Delikhoon, M., Mahvi, A.H., Rashidi, M., 2018. Characteristics and health effects of BTEX in a hot spot for urban pollution. Ecotoxicology and environmental safety. 155: 133-143.

Durmusoglu, E., Taspinar, F., Karademir, A., 2010. Health risk assessment of BTEX emissions in the landfill environment. Journal of hazardous materials. 176: 870-877.

Elkilani, A., Bouhamra, W., 2001. Estimation of optimum requirements for indoor air quality and energy consumption in some residences in Kuwait. Environment international. 27: 443-447.

Ferm, M., De Santis, F., Varotsos, C., 2005. Nitric acid measurements in connection with corrosion studies. Atmospheric Environment. 39: 6664-6672.

IARC:, 2012. evaluation of carcinogenic risks to humans, volumes 100F. Chemical Agents and Related Occupations 249e294. nternational Agency for Research on Cancer. 249e294.

Janitz, A.E., Campbell, J.E., Magzamen, S., Pate, A., Stoner, J.A., Peck, J.D., 2017. Benzene and childhood acute leukemia in Oklahoma. Environmental Research. 158: 167-173.

Kuwait Petroleum Cooperation, 2017. KPNC Annual Reports Kuwait.

Linet, M.S., Yin, S.N., Travis, L.B., Li, C.Y., Zhang, Z.N., Li, D.G., Rothman, N., Li, G.L., Chow, W.H., Donaldson, J., Dosemeci, M., Wacholder, S., Blot, W.J., Hayes, R.B., 1996. Clinical features of hematopoietic malignancies and related disorders among benzene-exposed workers in China. Benzene Study Group. Environmental Health Perspectives. 104: 1353-1364.

Miri, M., Shendi, M.R.A., Ghaffari, H.R., Aval, H.E., Ahmadi, E., Taban, E., Gholizadeh, A., Aval, M.Y., Mohammadi, A., Azari, A., 2016. Investigation of outdoor BTEX: Concentration, variations, sources, spatial distribution, and risk assessment. Chemosphere. 163: 601-609.

Oturakci, M., Dagsuyu, C., Derse, O., 2020. A new fuzzy approach in risk assessment with process capability for air pollution. Energy Sources, Part A: Recovery, Utilization, and Environmental Effects. 1-14.

Rezazadeh Azari, M., Naghavi Konjin, Z., Zayeri, F., Salehpour, S., Seyedi, M.D., 2012. Occupational exposure of petroleum depot workers to BTEX compounds. The international journal of occupational and environmental medicine. 3: 39-44.

Srivastava, A., Joseph, A.E., Devotta, S., 2006. Volatile organic compounds in ambient air of Mumbai-India. Atmospheric Environment. 40: 892-903.

WHO, 2000. Air quality guidelines for Europe. Environmental science and pollution research international. 3: 23.

WHO, 2010. WHO guidelinesfor indoor air quality: selected pollutants. 